\title{
Anti-NY-ESO-1 Research Paper Anti-NY-ESO-1 autoantibody may be a tumor marker for intrahepatic cholangiocarcinoma
}

\author{
Zhen Zhang ${ }^{1}$, Fan-Fan Lí ${ }^{2}$, Ming-Dian Lu' ${ }^{1}$, Shang-Xin Zhang ${ }^{1}$ and Yong-Xiang $\mathbf{L i}^{1}$ \\ ${ }^{1}$ Department of Gastrointestinal Surgery, The First Affiliated Hospital of Anhui Medical University, Hefei, China \\ ${ }^{2}$ Department of Oncology, The Second Affiliated Hospital of Anhui Medical University, Hefei, China \\ Correspondence to: Yong-Xiang Li, email: yongxiangli2001@outlook.com
}

Keywords: NY-ESO-1; antibody; intrahepatic cholangiocarcinoma; prognosis

Received: May 23, $2017 \quad$ Accepted: October 28, $2017 \quad$ Published: November 15, 2017

Copyright: Zhang et al. This is an open-access article distributed under the terms of the Creative Commons Attribution License 3.0 (CC BY 3.0), which permits unrestricted use, distribution, and reproduction in any medium, provided the original author and source are credited.

\section{ABSTRACT}

Anti-NY-ESO-1 antibody is observed in a multitude of malignancies. This study was aimed to evaluate the expression of serum anti-NY-ESO-1 antibodies and its prognostic value in intrahepatic cholangiocarcinoma. A total of 103 patients with intrahepatic cholangiocarcinoma were enrolled in the study. Enzyme-linked immunosorbent assay (ELISA) was performed to detect the serum level of anti-NYESO-1 antibody. Western blotting was performed to assess the NY-ESO-1 expression in tumor and adjacent tissues. The serum NY-ESO-1 antibody was detected in $\mathbf{1 8 . 4 \%}$ of patients with intrahepatic cholangiocarcinoma, a value that was significantly higher than that in patients with chronic Hepatitis B. Serum NY-ESO-1 antibody was positively correlated with tumor differentiation, lymphatic metastasis, cTNM stage and abdominal pain. Finally, there was a higher cumulative survival rate in patients with serum NY-ESO-1 positivity than in those with serum NY-ESO-1 negativity among the patients with stage III + IV. Our data uncovered that NY-ESO-1 antibody might be a helpful tumor marker and prognostic predictor in intrahepatic cholangiocarcinoma.

\section{INTRODUCTION}

Cholangiocarcinoma, a heterogeneous entity of malignancy derived from epithelial biliary cells, is classified into intrahepatic (iCCA), perihilar (pCCA) or distal cholangiocarcinomas according to different anatomical locations [1]. Cholangiocarcinoma is rare malignancy and accounts for $5 \%$ to $10 \%$ of the malignant tumors [2]. Since the high-level resistance to conventional antitumor agents and poor clinical outcome, surgical treatment is the preferred option and only curative treatment for all subtypes. However, the surgical treatment is hampered by the high incidence of recurrence and metastasis and a low 5-year overall survival rate [3]. Therefore, the identification of sensitive prognostic and predictive markers is of great clinical importance to the improvement of the curative rate and survival rate of the patients.

The analysis of serum tumor markers is used for screening, predicting response, and postoperative surveillance of malignancies including hepatobiliary cancer [4]. The combined determination of several nonspecific tumor markers, including cancer antigen (CA) 72-4, CA125, CA19-9 and carcinoembryonic antigen (CEA), is an effective method to monitor the treatment efficacy and predict tumor recurrence [5]. Previous studies have presented that post-operation monitoring of CEA and/or CA19-9 is useful to predict the recurrence or evaluate the response of patients with iCCA, especially patients with high preoperative levels of these markers $[6,7]$. However, these aforementioned markers are nonorgan-specific and merely available in disease activity evaluation and treatment efficacy monitoring, but not in the diagnosis of iCCA $[8,9]$.

The cancer/testis (CT) antigen of NY-ESO-1 was initially defined during the identification of immunogenic tumor antigens in the case of esophageal squamous cell carcinoma using the serological analysis of recombinant cDNA expression libraries (SEREX) [10, 11]. Further studies have demonstrated that humoral immunity to 
NY-ESO-1, with the spontaneous production of NY-ESO-1 antibody, is clearly antigen driven because it is reduced with tumor resection or histopathological regression [12]. The frequency of NY-ESO-1 antibody was $9.4 \%$ in melanoma patients, $12.5 \%$ in ovarian cancer patients, $3.8-52 \%$ in prostate cancer patients, and $9-23 \%$ in lung cancer patients; on the other hand, NY-ESO-1 antibody has not been found in non-cancerous patients or healthy control subjects [13-16]. These findings revealed that NY-ESO-1 antibody may be a promising candidate for the cancer diagnosis and immunotherapy of various cancers.

However, there were rare reports focused on the expression of NY-ESO-1 gene or antigen in iCCA $[17,18]$ and no study was conducted for the correlation between serum antibody against NY-ESO-1 and survival of patients with cholangiocarcinoma especially iCCA. The aim of this study was to investigate the expression of NY-ESO-1 antibody and its association with different clinicopathological features and the survival rate of patients with iCCA.

\section{RESULTS}

\section{Clinical profile of enrolled subjects and NY-ESO-1 antibody levels}

The clinical characteristics and serum level of NYESO-1 antibody of the subjects are demonstrated in Table 1. A total of 103 patients with iCCA and $108 \mathrm{CHB}$ patients matched for age and sex were recruited in this study. In patients with iCCA and $\mathrm{CHB}$, the mean ages were $65.4 \pm 13.4$ and $62.7 \pm 15.2$ years, respectively; the percentages of female patients were $67.0 \%$ (69/103) and $64.8 \%$ (70/108), respectively. There was significant difference between the two populations in AFP level $(36.4 \pm 13.1 \mathrm{ng} / \mathrm{ml}$ vs. $7.1 \pm 20.5 \mathrm{ng} / \mathrm{ml})$, total bilirubin (T-Bil) $(124.9 \pm 35.7 \mu \mathrm{mol} / \mathrm{L}$ vs. $38.3 \pm 12.2 \mu \mathrm{mol} / \mathrm{L})$, and direct bilirubin (D-Bil) $(23.7 \pm 36.2 \mu \mathrm{mol} / \mathrm{L}$ vs. $15.6 \pm 11.1 \mu \mathrm{mol} / \mathrm{L}$ ) (all $p<0.001$ ), respectively. Most importantly, the positivity of NY-ESO-1 antibody was $18.4 \%(19 / 103)$ in patients with iCCA, which was significantly higher than that in patients with $\mathrm{CHB}$ $(3.7 \%, 4 / 108)(p<0.001)$. The median duration of followup was 24 months (range, 1-36 months).

\section{Serum NY-ESO-1 antibody and pathological features of iCCA}

There were $21.1 \%$ (4/19) of well differentiated and $78.9 \%(15 / 19)$ of poorly differentiated iCCAs in serum NY-ESO-1 antibody-positive patients, leading to a significantly different distribution of histological grade between iCCA patients with different NY-ESO-1 humoral immune responses $(p=0.01)$. However, there was no significant difference in tumor size $(p=0.60)$, portal invasion $(p=0.06)$ and liver cirrhosis $(p=0.82)$ between
NY-ESO-1 antibody-positive and -negative patients $(p>0.05)$. Furthermore, the relationship between NY-ESO-1 antibody positivity and lymphatic metastasis and clinical TNM (cTNM) stage of iCCA were analyzed. The results demonstrated that a significant difference in lymphatic metastasis and cTNM stage was found between the positive expression of serum NY-ESO-1 and cTNM stage ( $p=0.04$ and $p=0.03$, respectively) (Table 2 ).

\section{Expression of NY-ESO-1 protein in iCCA tissue}

Immunohistochemical staining was performed to show the NY-ESO-1 protein expression. Our results suggested that there was positive staining of NY-ESO-1 in both membrane and cytoplasm of tumor cells (Figure 1A-1D). Then, the expression of NY-ESO-1 in iCCA tissue and adjacent nonneoplastic tissues was validated using standard Western blotting procedures. The tissue specimens were obtained from all patients with iCCA. Our results indicated that the NY-ESO-1 protein expression in iCCA tissue, especially in those with higher stages from III to IV, was significantly upregulated compared with that in adjacent tissues $(p<0.01)$ (Figure 1E, 1F).

\section{Correlation between serum anti-NY-ESO-1 antibody and initial symptoms of iCCA}

The correlation analysis between serum NY-ESO-1 antibody and initial symptoms was performed using univariate logistic regression analysis. Our findings showed that the serum level of NY-ESO-1 antibody is closely associated to abdominal pain (crude odds ratio [cOR] 4.53, 95\% CI 1.29-8.31, $p<0.001)$ and jaundice/ pruritus (cOR 1.28, 95\% CI 1.30-4.23, $p=0.02$ ). After adjustment of related co-variables in multivariate model included age, gender, smoking, alcohol drinking, AFP, T-Bil and D-Bil, the positivity of serum anti-NY-ESO-1 antibody was correlated with abdominal pain (adjusted odds ratio [aOR] 2.66; 95\% CI 1.10-4.47, $p=0.04$ ) in iCCA patients. However, in multivariate model, no significant correlation was found between the serum level of NY-ESO-1 antibody and that of fever $(p=0.68)$, nausea $(p=0.57)$, emesis $(p=0.62)$, jaundice/pruritus $(p=0.39)$, anorexia $(p=0.55)$, and asymptomatic demonstration $(p=0.84)$, respectively (Table 3$)$.

\section{Prognostic performance of serum anti-NY-ESO-1 antibody in iCCA}

The effects of serum anti-NY-ESO-1 antibody on the prognosis of iCCA patients were assessed using Kaplan-Meier survival analysis with log-rank testing. In iCCA patients at stage I + II, there was no association between the cumulative survival rate and positivity of the serum anti-NY-ESO-1 antibody ( $p=0.52$ ) (Figure 2A). However, among the iCCA patients with stage III + IV, 
Table 1: Characteristics of the subjects and expression of anti-NY-ESO-1 antibody

\begin{tabular}{|c|c|c|c|}
\hline & $\operatorname{ICC}(n=103)$ & CHB $(n=108)$ & $\boldsymbol{P}$ \\
\hline Age (year) & $65.4 \pm 13.4$ & $62.7 \pm 15.2$ & 0.67 \\
\hline Gender (female, \%) & $69(67.0)$ & $70(64.8)$ & 0.28 \\
\hline Smoking $(n, \%)$ & $54(52.4)$ & $61(56.5)$ & 0.49 \\
\hline Alcohol drinking $(n, \%)$ & $46(44.7)$ & $58(53.7)$ & 0.07 \\
\hline Anti-NY-ESO-1 $(n, \%)$ & $19(18.4)$ & $4(3.7)$ & $<0.001$ \\
\hline \multicolumn{4}{|l|}{ Laboratory parameters } \\
\hline Anti-HBV $(+)(n, \%)$ & $49(47.6)$ & $56(51.9)$ & 0.49 \\
\hline $\operatorname{AFP}(n g / m l)$ & $36.4 \pm 13.1$ & $7.1 \pm 20.5$ & $<0.001$ \\
\hline T-Bil $(\mu \mathrm{mol} / \mathrm{L})$ & $124.9 \pm 35.7$ & $38.3 \pm 12.2$ & $<0.001$ \\
\hline D-Bil $(\mu \mathrm{mol} / \mathrm{L})$ & $23.7 \pm 36.2$ & $15.6 \pm 11.1$ & $<0.001$ \\
\hline AST (U/L) & $57.2 \pm 11.2$ & $66.2 \pm 15.2$ & 0.81 \\
\hline ALT (U/L) & $54.2 \pm 20.3$ & $56.1 \pm 37.3$ & 0.79 \\
\hline GGT (U/L) & $165.3 \pm 435.2$ & $162.2 \pm 31.5$ & 0.45 \\
\hline
\end{tabular}

ICC: Intrahepatic cholangiocarcinoma; CHB: Chronic Hepatitis B.

Table 2: The relationship between positivity of anti-NY-ESO-1 antibodies and pathological characteristics

\begin{tabular}{|c|c|c|c|}
\hline Characteristic & $\begin{array}{c}\text { Anti-NY-ESO-1 (+) } \\
(n=19)\end{array}$ & $\begin{array}{c}\text { Anti-NY-ESO-1 (-) } \\
(n=84)\end{array}$ & $\boldsymbol{P}$ \\
\hline \multicolumn{4}{|l|}{ Differentiation $(n, \%)$} \\
\hline Well differentiation & $4(21.1)$ & $44(52.4)$ & 0.01 \\
\hline Poorly differentiation & $15(78.9)$ & $40(47.6)$ & \\
\hline \multicolumn{4}{|l|}{ Tumor size $(n, \%)$} \\
\hline$\leq 5 \mathrm{~cm}$ & $6(31.6)$ & $32(38.1)$ & 0.60 \\
\hline$>5 \mathrm{~cm}$ & $13(68.4)$ & $52(61.9)$ & \\
\hline \multicolumn{4}{|l|}{ Portal invasion } \\
\hline Yes & $12(63.2)$ & $33(39.3)$ & 0.06 \\
\hline No & $7(36.8)$ & $51(60.7)$ & \\
\hline \multicolumn{4}{|c|}{ Lymphatic metastasis $(n, \%)$} \\
\hline Yes & $11(57.9)$ & $27(32.1)$ & 0.04 \\
\hline No & $8(42.1)$ & $57(67.9)$ & \\
\hline \multicolumn{4}{|l|}{ Liver cirrhosis } \\
\hline Yes & $9(47.4)$ & $39(46.4)$ & 0.82 \\
\hline No & $10(52.6)$ & $45(43.6)$ & \\
\hline \multicolumn{4}{|l|}{ cTNM stage $(n, \%)$} \\
\hline $\mathrm{I}+\mathrm{II}$ & $6(31.6)$ & $50(59.5)$ & 0.03 \\
\hline III + IV & $13(68.4)$ & $34(40.5)$ & \\
\hline
\end{tabular}

the cumulative survival rate was higher in serum NY-ESO1-positive patients than in NY-ESO-1-negative patients $(p=0.034)$ (Figure 2B).

\section{DISCUSSION}

This study documents that there is a higher frequency of serum NY-ESO-1 antibody in iCCA patients
$18.4 \%(19 / 103)$ than in patients with CHB $(3.7 \%, 4 / 108)$. The serum level of NY-ESO-1 antibody is correlated with pathological characteristics including tumor poorly differentiation and lymphatic metastasis and a higher cTNM stage. However, our results suggest a possibility that serum NY-ESO-1 antibody, induced in naturally occurring immune responses, might be a beneficial factor in prolonging the overall survival of iCCA. 
The gene for NY-ESO-1 was localized to chromosome $\mathrm{Xq} 28$, a region that also includes the MAGE family that encodes protein with a characteristic of cancer or testis expression pattern [19]. The expression of NY-ESO-1 mRNA was revealed in $20-30 \%$ of esophageal cancer, melanomas, advanced prostate cancer, hepatocellular carcinoma, epithelial ovarian cancer, breast tumors, and bladder cancers [10, 14, 20, 21]. The NY-ESO-1 gene codes for an 18-kDa immunogenic testicular antigen [22]. Previous studies have suggested that the NY-ESO-1 product appears to be the most immunogenic, eliciting both humoral and cellular immunological response in a high percentage of patients with advanced NY-ESO-1expressing tumors $[12,13,22,23]$.

NY-ESO-1, as the most immunogenic CT antigen known thus far, is widely expressed and is considered a potential target molecule for cancer vaccines in a multitude of malignancies as described above [24]. The NY-ESO-1-induced humoral immune response was lower in early-stage tumor (stage I and II) than in those with higher stage (stage III and IV) in, for instance, gastric cancer, making the NY-ESO-1 antibody insufficient for the early prediction [9]. However, as NY-ESO-1 protein is expressed in only tumor tissues and the NY-ESO-1 antibody was strictly developed by the NY-ESO-1 antigen in tumor tissue, extremely highly specific NY-ESO-1 humoral immune responses were detected in NY-ESO-1expressing cancer patients [13]. This was also confirmed by this study in which the frequencies of antibody against NY-ESO-1 were only $3.7 \%$ in non-neoplastic disease such as $\mathrm{CHB}$.

The role of antibody against CT family antigens in predicting the survival of tumor patients is controversial. In ovarian cancer, antibodies against any of the MAGE
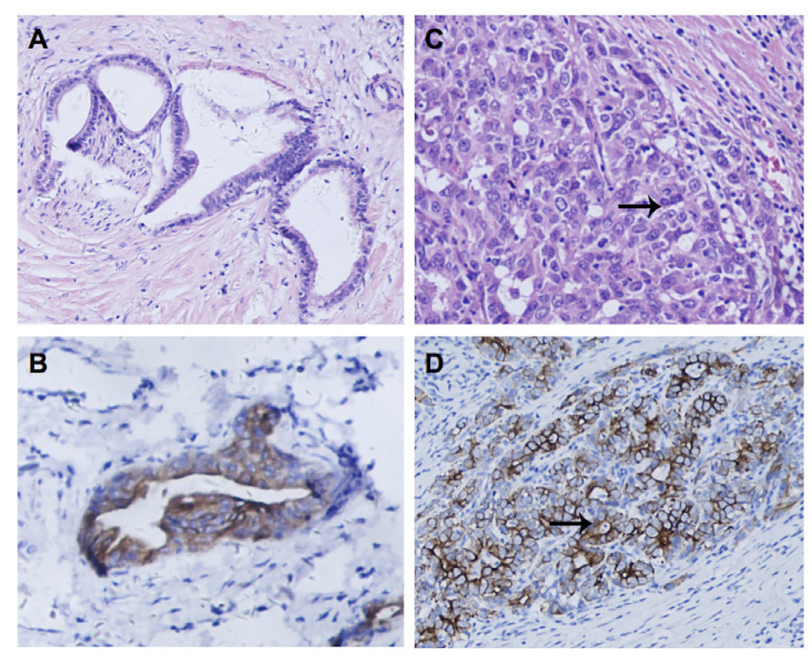

$E$
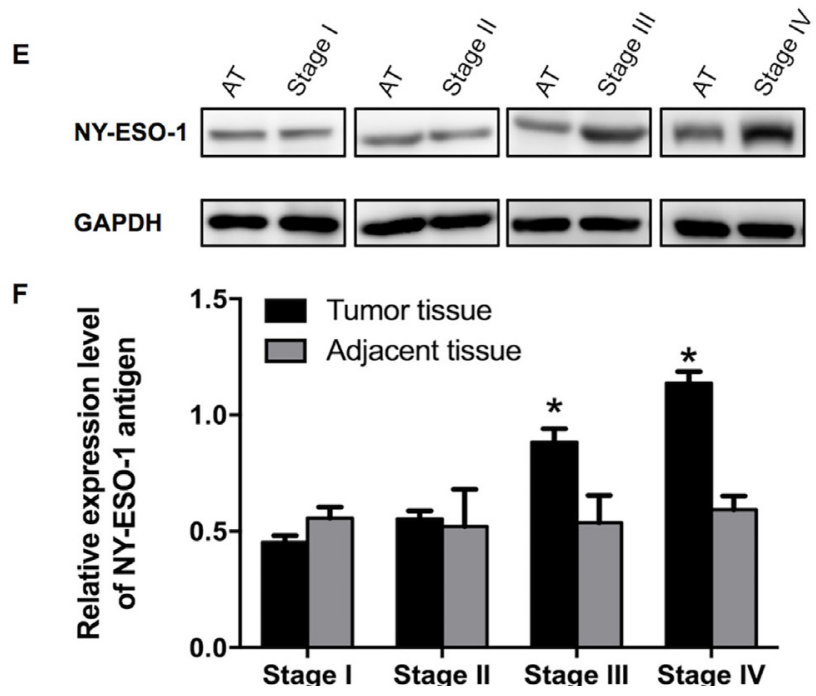

Figure 1: Expression of NY-ESO-1 antigen in iCCA and corresponding adjacent normal tissues. (A-D) Representative H\&E staining demonstrate the well (A) and poorly (C) differentiated iCCA tissues; Immunohistochemical micrographs show the expression of NY-ESO-1 in well (B) and poorly (D) differentiated carcinoma (Original magnification: $\times 400)$. (E, F) NYESO-1 antigen expression was significantly increased in iCCA tissue, especially in tissues with stage III and IV disease, compared with that in adjacent non-neoplastic tissues (E, F). (AT: adjacent tissues.) 
Table 3: The correlation between anti-NY-ESO-1 positivity and the initial symptoms of intrahepatic cholangiocarcinoma

\begin{tabular}{|c|c|c|c|c|}
\hline \multirow{2}{*}{ Initial demonstration } & \multicolumn{2}{|c|}{ Univariate associations } & \multicolumn{2}{|c|}{ Multivariate associations } \\
\hline & Crud Odd ratio & $P$ value & Adjusted Odd ratio & $P$ value \\
\hline Fever & $1.83(0.78-2.01)$ & 0.45 & $1.06(0.69-1.43)$ & 0.68 \\
\hline Abdominal pain & $4.53(1.29-8.31)$ & $<0.001$ & $2.66(1.10-4.47)$ & 0.04 \\
\hline Nausea & $1.99(0.61-1.56)$ & 0.26 & $0.95(0.48-1.22)$ & 0.57 \\
\hline Emesis & $1.29(0.81-3.27)$ & 0.24 & $0.66(0.79-2.04)$ & 0.62 \\
\hline Jaundice/pruritus & $1.28(1.30-4.23)$ & 0.02 & $0.97(0.80-3.19)$ & 0.39 \\
\hline Anorexia & $1.58(0.34-5.89)$ & 0.43 & $1.02(0.46-3.37)$ & 0.55 \\
\hline Asymptomatic & $1.05(0.64-5.73)$ & 0.72 & $0.89(0.48-4.41)$ & 0.84 \\
\hline
\end{tabular}

recruited from 2002 to 2016 and the study was conducted in October 2016. In total, 150 hospitalized patients with histologically confirmed iCCA, who underwent surgical resection or chemotherapy at the Department of Gastrointestinal Surgery, the First Affiliated Hospital of Anhui Medical University, were enrolled in the study. Finally, complete follow-up was obtained in 103 $(68.7 \%)$ patients at the end of this study. Additionally, 108 hospitalized patients with chronic hepatitis B (CHB) matched for age and sex were also recruited as controls in this study.

The serum samples were collected and stored as surplus samples after routine blood tests for patients with iCCA and as part of a routine examination for control subjects. The flash-frozen tissue specimens of tumor and adjacent tissues were obtained from iCCA patients and were stored at $-80^{\circ} \mathrm{C}$. Finally, the relevant patient databases were retrieved to collect medical information, including blood test results, tumor stage, histological type, invasion location, and lymphatic metastasis, which were obtained from pathological examinations and/or radiographic findings.

\section{Enzyme-linked immunosorbent assay (ELISA)}

Anti-NY-ESO-1 antibodies were detected by ELISA. Polystyrene plates (96-well) were coated and incubated overnight at $4^{\circ} \mathrm{C}$ with $100 \mu \mathrm{L} /$ well of recombinant human protein NY-ESO-1 $(1 \mu \mathrm{g} / \mathrm{ml})$ in phosphate-buffered saline (PBS) on the test half and PBS alone on the control half. The coated plates were washed 3 times with PBS containing $0.1 \%$ Tween 20 (PBS-T) and were blocked for $2 \mathrm{~h}$ at room temperature with $200 \mu \mathrm{L}$ of $1 \%$ BSA in PBS. After washing 3 times again with PBS-T, the wells were incubated for $1 \mathrm{~h}$ at room temperature with $100 \mu \mathrm{L}$ of patient serum (diluted 1:100 in the blocking buffer). Next, after extensive washing, Horseradish-Peroxidase goat anti-human IgG/polyclonal (Sigma-Aldrich, St. Louis, MO) was diluted in $1 \%$ BSA in PBS and was added to the wells as a secondary antibody, and the plates were incubated for $1 \mathrm{~h}$ at room temperature. The plates were washed 3 times with PBS-T; the bound peroxidase was then revealed with $100 \mu \mathrm{L}$ of O-phenylenediamine dihydrochloride, and the signal development was stopped with $0.2 \mathrm{M} \mathrm{H}_{2} \mathrm{SO}_{4}$ incubation for $5 \mathrm{~min}$. Absorbance
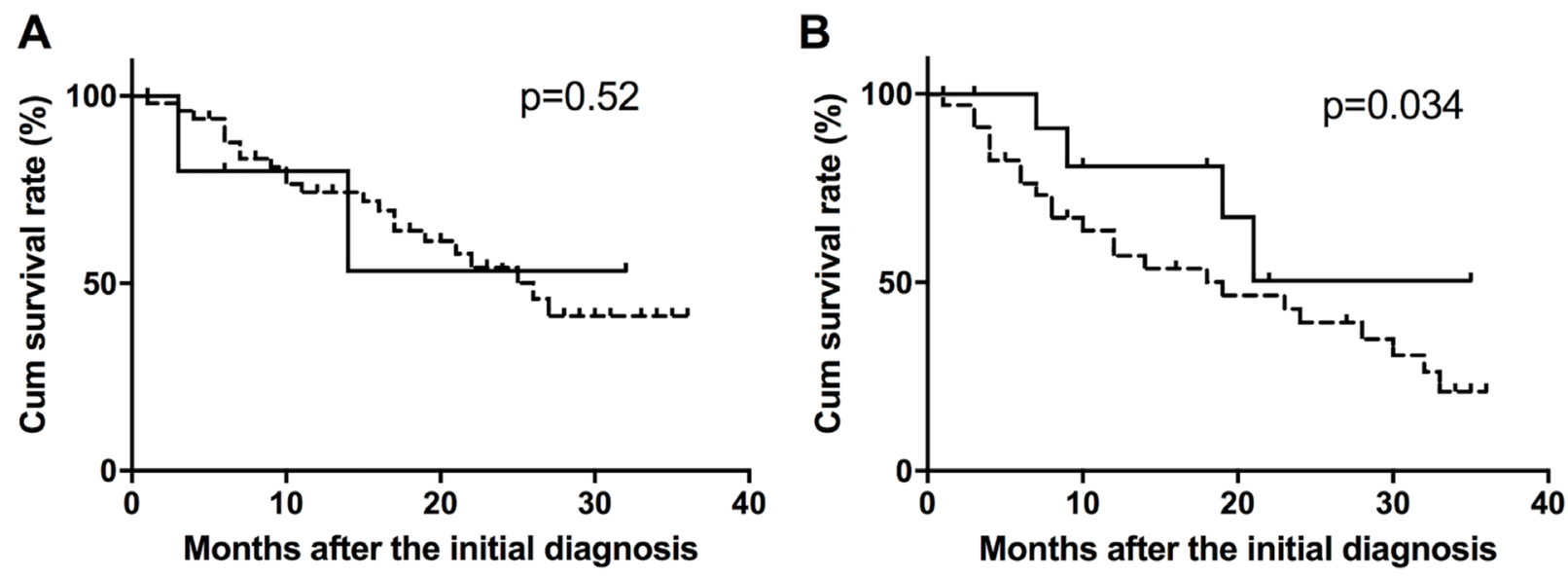

Figure 2: Survival curves of NY-ESO-1 antibody-positive and -negative patients. The cumulative survival rate was calculated in iCCA patients with stage I + II (A) and stage III + IV (B) disease. 
was measured at $492 \mathrm{~nm}$ using a microplate reader. The data are presented as the mean optical density (OD) adjusted for background (wells coated with PBS alone). A cut-off value was defined as the mean optical density (OD) \pm 3 SD of normal human sera. Each serum sample was analyzed in triplicate. Ovalbumin (OVA, Sigma Aldrich) was employed as a control protein [9].

\section{Immunohistochemistry}

Four-micron thick formalin-fixed, paraffinembedded tissue sections were used. The sections were deparaffinized in xylene and rehydrated in graded alcohols (100\%, 95\% and 85\%). After heat-induced epitope retrieval by retrieval solution $(10 \mathrm{mM}$ citrate buffer, $\mathrm{pH}$ 6.0) for $30 \mathrm{~min}$, endogenous peroxidase was blocked using the Blocking Kit (Zhongshan Biotechnology, Beijing, China). Slides were then incubated with the primary antibodies against NY-ESO-1 (1:100 dilution, Invitrogen/ Life Technologies, NY) at room temperature for $2 \mathrm{~h}$. A horseradish peroxidase/3,3'-diaminobenzidine polymerbased detection system (DAKO; Envision+ System, CA) was utilized for detection of the NY-ESO-1 expression. NY-ESO-1 staining was defined as positive when the nuclear and/or cytoplasmic staining was detected.

\section{Western blotting analysis}

The frozen tissue specimens were homogenized, lysed with pre-cooled RIPA lysis solution for $50 \mathrm{~min}$ at $4^{\circ} \mathrm{C}$ and then centrifuged at $12,000 \mathrm{~g} / \mathrm{min}$ for $5 \mathrm{~min}$ for protein extraction. The concentration of the total protein in the supernatant was detected using the BCA-Protein Assay Kit (Thermo Scientific, USA). The total proteins were analyzed using SDS-PAGE electrophoresis and then were transferred to polyvinylidene difluoride (PVDF) membranes by an electroblot apparatus. After blocking with defatted milk for $1 \mathrm{~h}$ at $25^{\circ} \mathrm{C}$, the primary rabbit anti-NYESO-1/polyclonal antibodies (1:1000, Abcam, Cambridge, MA) and mouse anti-GAPDH/polyclonal (1:5000, Abcam, Cambridge, MA) were added and incubated on a shaker overnight at $4^{\circ} \mathrm{C}$. After rinsing with PBS $(10 \min \times 3)$, HRP-labeled secondary rabbit or mouse IgG antibodies/ polyclonal (1:5000, Abcam, Cambridge, MA) were added and incubated at room temperature for $1 \mathrm{~h}$. The protein was determined by the enhanced chemiluminescence (ECL) detection system. Imaging signals of protein bands were acquired and analyzed using Image Lab Software (Biorad, Richmond, CA). The relative expression of NY-ESO-1 protein was defined as the ratio of gray values between the target protein and GADPH.

\section{Statistical analysis}

All of the data were analyzed using SPSS 23.0 software (SPSS, USA). The distributions of the NY-ESO-1 antibody in different groups were analyzed by $\chi^{2}$ test.
The effect of NY-ESO-1 antibody on the cumulative survival rate was plotted using Kaplan-Meier curves and log-rank testing. Values of $p<0.05$ were considered statistically significant.

\section{Author contributions}

zhen Zhang and Shang-xin Zhang collected the materials, analyzed and interpreted the data; Zhen Zhang and Fan-fan Li wrote the manuscript. Zhen Zhang and Yong-xiang Li provided the conception and design of the manuscript. All of the authors have read and approved the final version to be published.

\section{ACKNOWLEDGMENTS}

We gratefully appreciate the efforts and contributions of doctors, nurses, and technical staff at The First Hospital of Anhui Medical University.

\section{CONFLICTS OF INTEREST}

All authors do not have any conflicts of interest.

\section{GRANT SUPPORT}

This study was supported by the Science and Technique Foundation of Anhui Province (Grant No. 1401045015) and the Outstanding Young Researchers Foundation in Colleges of Anhui Province.

\section{REFERENCES}

1. Razumilava N, Gores GJ. Cholangiocarcinoma. Lancet. 2014; 383:2168-2179.

2. Siegel RL, Miller KD, Jemal A. Cancer statistics, 2016. CA Cancer J Clin. 2016; 66:7-30.

3. Spolverato G, Kim Y, Ejaz A, Alexandrescu S, Marques H, Aldrighetti L, Gamblin TC, Pulitano C, Bauer TW, Shen F, Sandroussi C, Poultsides G, Maithel SK, et al. Conditional Probability of Long-term Survival After Liver Resection for Intrahepatic Cholangiocarcinoma: A Multiinstitutional Analysis of 535 Patients. JAMA surgery. 2015; 150:538-545.

4. Charatcharoenwitthaya P, Enders FB, Halling KC, Lindor KD. Utility of serum tumor markers, imaging, and biliary cytology for detecting cholangiocarcinoma in primary sclerosing cholangitis. Hepatology. 2008; 48:1106-1117.

5. Lai IR, Lee WJ, Huang MT, Lin HH. Comparison of serum CA72-4, CEA, TPA, CA19-9 and CA125 levels in gastric cancer patients and correlation with recurrence. Hepatogastroenterol. 2002; 49:1157.

6. Levy C, Lymp J, Angulo P, Gores GJ, Larusso N, Lindor KD. The Value of Serum CA 19-9 in Predicting 
Cholangiocarcinomas in Patients with Primary Sclerosing Cholangitis. Digest Dis Sci. 2005; 50:1734-1740.

7. Anderson CD, Pinson CW, Berlin J, Chari RS. Diagnosis and treatment of cholangiocarcinoma. Oncologist. 2004; 9:43-57.

8. Takahashi Y, Mai M, Kusama S. Factors influencing growth rate of recurrent stomach cancers as determined by analysis of serum carcinoembryonic antigen. Cancer. 1995; 75:1497-1502.

9. Fujiwara S, Wada H, Kawada J, Kawabata R, Takahashi T, Fujita J, Hirao T, Shibata K, Makari Y, Iijima S, Nishikawa H, Jungbluth AA, Nakamura Y, et al. NY-ESO-1 antibody as a novel tumour marker of gastric cancer. Br J Cancer. 2013; 108:1119-1125.

10. Chen YT, Scanlan MJ, Sahin U, Tureci O, Gure AO, Tsang S, Williamson B, Stockert E, Pfreundschuh M, Old LJ. A testicular antigen aberrantly expressed in human cancers detected by autologous antibody screening. Proc Natl Acad Sci U S A. 1997; 94:1914-1918.

11. Endo M, de Graaff MA, Ingram DR, Lim S, Lev DC, Briaire-de Bruijn IH, Somaiah N, Bovee JV, Lazar AJ, Nielsen TO. NY-ESO-1 (CTAG1B) expression in mesenchymal tumors. Mod Pathol. 2015; 28:587-595.

12. Jager E, Stockert E, Zidianakis Z, Chen YT, Karbach J, Jager D, Arand M, Ritter G, Old LJ, Knuth A. Humoral immune responses of cancer patients against "CancerTestis" antigen NY-ESO-1: correlation with clinical events. Int J Cancer. 1999; 84:506-510.

13. Stockert E, Jager E, Chen YT, Scanlan MJ, Gout I, Karbach J, Arand M, Knuth A, Old LJ. A survey of the humoral immune response of cancer patients to a panel of human tumor antigens. J Exp Med. 1998; 187:1349-1354.

14. Nakada T, Noguchi Y, Satoh S, Ono T, Saika T, Kurashige T, Gnjatic S, Ritter G, Chen YT, Stockert E, Nasu Y, Tsushima T, Kumon $\mathrm{H}$, et al. NY-ESO-1 mRNA expression and immunogenicity in advanced prostate cancer. Cancer Immun. 2003; 3:10.

15. Gati A, Lajmi N, Derouiche A, Marrakchi R, Chebil M, Benammar-Elgaaied A. NY-ESO-1 expression and immunogenicity in prostate cancer patients. Tunis Med. 2011; 89:779-783.

16. Tureci $\mathrm{O}$, Mack $\mathrm{U}$, Luxemburger $\mathrm{U}$, Heinen $\mathrm{H}$, Krummenauer F, Sester M, Sester U, Sybrecht GW, Sahin U. Humoral immune responses of lung cancer patients against tumor antigen NY-ESO-1. Cancer Lett. 2006; 236:64-71.

17. Utsunomiya $\mathrm{T}$, Inoue $\mathrm{H}$, Tanaka F, Yamaguchi $\mathrm{H}$, Ohta $\mathrm{M}$, Okamoto M, Mimori K, Mori M. Expression of cancer-testis antigen (CTA) genes in intrahepatic cholangiocarcinoma. Ann Surg Oncol. 2004; 11:934-940.
18. Zhou JX, Li Y, Chen SX, Deng AM. Expression and prognostic significance of cancer-testis antigens (CTA) in intrahepatic cholagiocarcinoma. J Exp Clin Cancer Res. $2011 ; 30: 2$.

19. Chen YT, Boyer AD, Viars CS, Tsang S, Old LJ, Arden KC. Genomic cloning and localization of CTAG, a gene encoding an autoimmunogenic cancer-testis antigen NY-ESO-1, to human chromosome Xq28. Cytogenet Cell Genet. 1997; 79:237-240.

20. Korangy F, Ormandy LA, Bleck JS, Klempnauer J, Wilkens L, Manns MP, Greten TF. Spontaneous tumor-specific humoral and cellular immune responses to NY-ESO-1 in hepatocellular carcinoma. Clin Cancer Res. 2004; 10:4332-4341.

21. Fujita S, Wada H, Jungbluth AA, Sato S, Nakata T, Noguchi Y, Doki Y, Yasui M, Sugita Y, Yasuda T, Yano M, Ono T, Chen YT, et al. NY-ESO-1 expression and immunogenicity in esophageal cancer. Clin Cancer Res. 2004; 10:6551-6558.

22. Jager E, Nagata Y, Gnjatic S, Wada H, Stockert E, Karbach J, Dunbar PR, Lee SY, Jungbluth A, Jager D, Arand M, Ritter G, Cerundolo V, et al. Monitoring CD8 T cell responses to NY-ESO-1: correlation of humoral and cellular immune responses. Proc Natl Acad Sci U S A. 2000; 97:4760-4765.

23. Odunsi K, Jungbluth AA, Stockert E, Qian F, Gnjatic S, Tammela J, Intengan M, Beck A, Keitz B, Santiago D, Williamson B, Scanlan MJ, Ritter G, et al. NY-ESO-1 and LAGE-1 cancer-testis antigens are potential targets for immunotherapy in epithelial ovarian cancer. Cancer Res. 2003; 63:6076-6083.

24. Scanlan MJ, Simpson AJ, Old LJ. The cancer/testis genes: review, standardization, and commentary. Cancer Immun. 2004; 4:1.

25. Daudi S, Eng KH, Mhawech-Fauceglia P, Morrison C, Miliotto A, Beck A, Matsuzaki J, Tsuji T, Groman A, Gnjatic S, Spagnoli G, Lele S, Odunsi K. Expression and immune responses to MAGE antigens predict survival in epithelial ovarian cancer. PLoS One. 2014; 9:e104099.

26. Ohue Y, Wada H, Oka M, Nakayama E. Antibody response to cancer/testis (CT) antigens: A prognostic marker in cancer patients. Oncoimmunology. 2014; 3:e970032.

27. Weide B, Martens A, Zelba H, Stutz C, Derhovanessian E, Di Giacomo AM, Maio M, Sucker A, Schilling B, Schadendorf D, Buttner P, Garbe C, Pawelec G. Myeloidderived suppressor cells predict survival of patients with advanced melanoma: comparison with regulatory $\mathrm{T}$ cells and NY-ESO-1- or melan-A-specific T cells. Clin Cancer Res. 2014; 20:1601-1609. 